\title{
Inter-annual variations in water yield to lakes in northeastern Alberta: implications for estimating critical loads of acidity
}

\author{
John J. GIBSON*, S. Jean BIRKS ${ }^{1)}$, Sanjeev KUMAR, Preston M. McEACHERN ${ }^{2)}$ and Roderick HAZEWINKEL ${ }^{2)}$ \\ Department of Geography, University of Victoria, Victoria, BC V8W 3P5, Canada \\ Alberta Research Council, Victoria, BC V8Z 7X8, Canada \\ ${ }^{1)}$ Alberta Research Council, Calgary, AB T2L 2A6, Canada \\ ${ }^{2)}$ Alberta Environment, $12^{\text {th }}$ Floor, Baker Centre, 10025-106 Street, Edmonton, AB T5J 1G4, Canada \\ *e-mail corresponding author: jjgibson@uvic.ca
}

\begin{abstract}
Stable isotopes of water were applied to estimate water yield to fifty lakes in northeastern Alberta as part of an acid sensitivity study underway since 2002 in the Athabasca Oil Sands Region (AOSR). Herein, we apply site-specific water yields for each lake to calculate critical loads of acidity using water chemistry data and a steady-state water chemistry model. The main goal of this research was to improve site-specific critical load estimates and to understand the sensitivity to hydrologic variability across a Boreal Plains region under significant oil sands development pressure. Overall, catchment water yields were found to vary significantly over the seven year monitoring period, with distinct variations among lakes and between different regions, overprinted by inter-annual climate-driven shifts. Analysis of critical load estimates based on site-specific water yields suggests that caution must be applied to establish hydrologic conditions and define extremes at specific sites in order to protect more sensitive ecosystems. In general, lakes with low (high) water yield tended to be more (less) acid sensitive but were typically less (more) affected by interannual hydrological variations. While it has been customary to use long-term water yields to define a static critical load for lakes, we find that spatial and temporal variability in water yield may limit effectiveness of this type of assessment in areas of the Boreal Plain characterized by heterogeneous runoff and without a long-term lake-gauging network. Implications for predicting acidification risk are discussed for the AOSR.
\end{abstract}

Key words: runoff, stable isotopes, lakes, acid sensitivity, Boreal plain, Athabasca Oil Sands Region, Canada

\section{INTRODUCTION}

Concern over possible impacts of air pollution on aquatic and terrestrial ecosystems has fuelled research on the effects of acid deposition on ecosystem health in Canada and elsewhere (Beamish \& Harvey 1972; Dillon et al. 1978; Watt et al.1979). The concept of critical load of acidity, "the maximum deposition of acidifying compounds that will not cause chemical changes leading to long-term harmful effects on ecosystem structure and functions" (Nilsson \& Grennfelt 1988), was developed to support effects-based emission reductions. Critical load assessments are an important tool for setting goals for future acid deposition limits and can be used to guide national and international policy on reducing environmental impacts of air pollutants (Henriksen et al. 2002).

The Steady-State Water Chemistry (SSWC) model (Henriksen et al. 1988) is currently the primary model used for assessing critical loads of acidity (sulphur and nitrogen) for freshwater lakes in Canada. As input, the SSWC model requires the lake chemistry data $\left(\mathrm{Ca}^{2+}\right.$, $\mathrm{Mg}^{2+}, \mathrm{Na}^{+}, \mathrm{K}^{+}, \mathrm{Cl}^{-}, \mathrm{NO}_{3}{ }^{-}$, and $\mathrm{SO}_{4}{ }^{2-}$ ) as well as estimates of catchment runoff (aka water yield). There is general agreement among researchers that the estimation of critical load is a useful tool for assessing the sensitivity of an ecosystem to acid deposition. However, the quality of input parameters to the existing critical load models needs improvement along with identification of the uncertainty in these parameters (White et al. 2000; Heywood et al. 2006; Skeffington et al. 2007).

Water yield $\left(W_{Y}\right.$, i.e., runoff from the drainage basin area to the lake) is an input parameter to the SSWC model. The critical acid load according to the SSWC model is directly proportional to $W_{Y}$ (Bennett et al. 2008). In Canada, most of the runoff estimates presently used in the SSWC model are based on long-term averages of grid-based runoff potential, given by the precipitation minus evaporation deficit. As catchment studies have increasingly revealed a large complexity and heterogeneity of runoff behaviour (e.g., Silvapalan 2003), especially in low-relief areas of the Boreal Plains (e.g., Devito et al. 2005), interpolation of such hydrologic indicators to ungauged or data-sparse areas may lead to significant errors for individual sites. A new approach using isotope mass balance (IMB) has been proposed for assessing regional hydrological variability and for estimating site-specific $W_{Y}$ (Gibson et al. 2002). The isotopic approach is site-specific as it is based on direct lake water sampling at each site and relies on the inherent heavy isotope enrichment record of long-term flushing rates that is archived within water molecules. Stable isotopes of water record hydrologic variability 


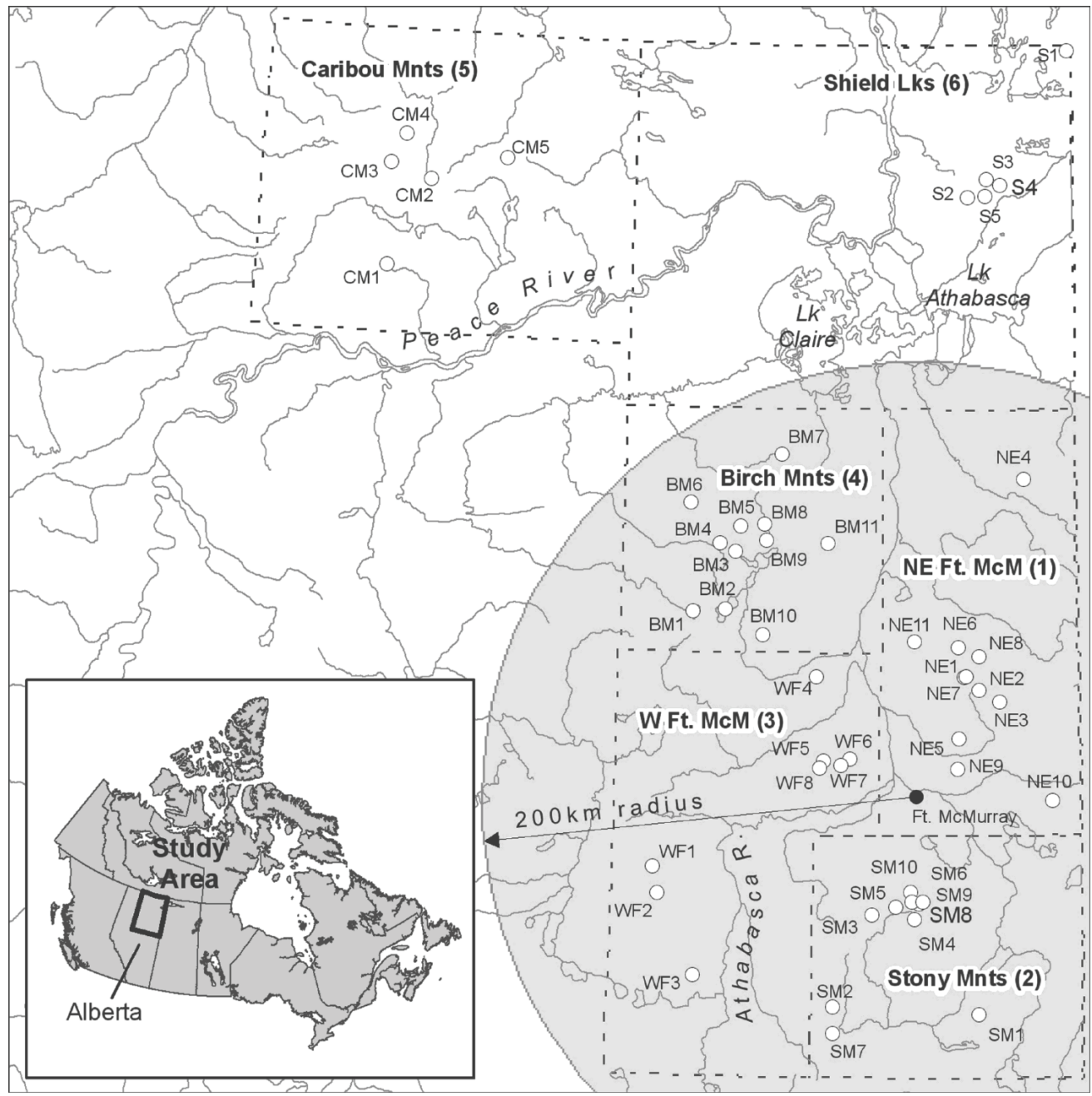

Fig. 1. Location of study lakes. The lakes are categorized within six regional study areas: (i) northeast Fort McMurray (NE); (ii) Stony Mountains (SM); (iii) West Fort McMurray (WF); (iv) Birch Mountains (BM); (5) Caribou Mountains (CM); and (6) Shield lakes (S) (after Bennett et al. 2008).

related both to macro-scale climate forcing but also, and importantly, due to heterogeneities in water routing, storage and runoff processes that accompany complex landscape/watershed patterns. Ongoing work has also included comparison of site specific $W_{Y}$ estimates with those derived using long-term average runoff in several western Canada acid sensitivity surveys (Gibson et al. 2010 , this issue). This comparison suggests that the use of long-term average runoff values in critical load calculation may overestimate the critical load for the majority of lakes.

This study, which takes advantage of regular timeseries sampling within a 50-lake water quality sampling network in northeastern Alberta operated since 2002, provide a new perspective on the inter-annual signals in hydrology and their impact on defining critical acid loads $\left(C L_{A}\right)$ for the region. The lakes in the network were selected as the most acid sensitive systems from among a total population of over 400 lakes previously surveyed in northeastern Alberta (WRS 2004), and are therefore anticipated to serve as a bellwether for poten- tial acidification. Related studies are also underway that contribute to better understanding of acidification processes, including tracing of hydrological flow paths and mapping connectivity of wetlands and lakes (e.g., Whitfield et al. 2010, in press; Schmidt et al. 2010, in press).

\section{MATERIAL AND METHODS}

\subsection{Site description}

The 50 study lakes (Fig. 1) are part of an on-going monitoring program of acid sensitive lakes in northeastern Alberta coordinated by Alberta Environment and the Regional Aquatics Monitoring Program (RAMP). Of the 50 lakes, 30 are situated within $200 \mathrm{~km}$ of Fort McMurray, the centre of oil sand development in the region, whereas five lakes are located in Caribou Mountains and four lakes located north of Lake Athabasca. These lakes are located in headwater catchments and range in size from shallow small ponds $(1 \mathrm{~m}$ depth, $<0.5 \mathrm{~km}^{2}$ ) to large lakes ( $30 \mathrm{~m}$ depth; $43 \mathrm{~km}^{2}$; Bennett et al. 2008). They also vary in their latitudinal position, 
morphometry, and associated landscape. The lakes are categorized within six regional study areas: (i) northeast Fort McMurray (NE); (ii) Stony Mountains (SM); (iii) West Fort McMurray (WF); (iv) Birch Mountains (BM); (5) Caribou Mountains (CM); and (6) Shield lakes (S). Detailed information about the study lakes and regional climatic conditions are described in Bennett et al. (2008).

\subsection{Data collection}

Sample collection and analyses: Water samples from the study lakes were collected for geochemical and isotopic $\left(\delta^{18} \mathrm{O}\right.$ and $\left.\delta^{2} \mathrm{H}\right)$ analysis during late summer of 2002 to 2008 using fixed-wing aircraft or helicopters. Geochemical analyses were carried out by Alberta Research Council, Vegreville, Alberta. Unfiltered water samples were collected from each lake in tightly-sealed high-density polyethylene bottles and analyzed for $\delta^{18} \mathrm{O}$ and $\delta^{2} \mathrm{H}$ at the Environmental Isotope Laboratory, University of Waterloo. In general, samples were collected from the depth-weighted water column when water bodies were well-mixed in late summer/fall. Details of the sampling protocol are described by Bennett et al. (2008). All isotope results are given in $\delta$ notation in permil (\%) relative to Vienna Standard Mean Ocean Water (V-SMOW) and normalized to the SMOW-SLAP scale (Standard Mean Ocean Water - Standard Light Antarctica Precipitation; Coplen 1996). Standard deviation of measurements, in general, was better than \pm $0.1 \%$ for $\delta^{18} \mathrm{O}$ and $\pm 0.4 \%$ for $\delta^{2} \mathrm{H}$.

Isotope Mass Balance (IMB) Method: Site-specific $W_{Y}$ during the present study was estimated using the IMB model developed under the assumptions of complete vertical mixing, constant density of water, and steady-state conditions, considered to be a reasonable approximation for Boreal lakes (e.g., Gibson et al. 2002; Bennett et al. 2008). The model determines flushing rates for each lake based on the degree of offset between the measured isotopic composition of lake water and estimated isotopic composition of precipitation at each site. The inflow volume to the lake and the proportion of this inflow entering vertically as precipitation and laterally as runoff $\left(W_{Y}\right)$ are subsequently calculated. A more detailed description of the method is given elsewhere (Gibson et al. 2002; Bennett et al. 2008). The $W_{Y}$ has been used to estimate the critical load during the present study.

Watershed, climate, and isotopic parameters: Application of the IMB model requires inputs, such as watershed and lake parameters (watershed area, lake area, and lake elevation), climatological parameters (precipitation, relative humidity, surface evaporation, and temperature), and precipitation isotope compositions (Gibson et al. 2002).

Watershed and lake parameters for each lake were compiled using Geographic Information Systems (GIS). Using the coordinates (latitude, longitude) for each lake, watershed area, lake area, and lake elevation were obtained using digital elevation data in raster format, corresponding to the 1: 50K NTS map sheets.

The climatological parameters were obtained from the North American Regional Reanalysis (NARR) dataset (Mesinger et al. 2006). The NARR dataset is a longterm, dynamically consistent, high-resolution, high-frequency, atmospheric and land surface hydrology dataset for the North American domain. The model has a horizontal resolution of $32 \mathrm{~km}$ and 45 layers in the vertical providing a much higher resolution than the global reanalysis datasets.

Monthly precipitation $\delta^{18} \mathrm{O}$ estimates were obtained for each lake location based on maps of Bowen and Wilkinson (2002), based on monthly observational data optimized for spatial interpolation using empirically derived relationships between latitude and elevation. The $\delta^{2} \mathrm{H}$ composition of monthly precipitation was calculated assuming that precipitation would follow the relationship defined by the Global Meteoric Water Line (GMWL; Craig 1961).

The details of the methodology employed to obtain all these input parameters are described in Gibson et al. (2010) of this issue.

\subsection{Critical load model}

A first approximation of critical loads of acidity $\left(C L_{A}\right)$ was performed during the present study using the SSWC model (Henriksen et al. 1992).

$$
C L_{A}=\left([B C]_{0}-\left[A N C_{\lim }\right]\right) \cdot W_{Y}
$$

This equation uses $W_{Y}\left(\mathrm{~m} \mathrm{y}^{-1}\right)$ to represent the flux (mass $\times$ time) of the annual average net catchment runoff. $\mathrm{BC}_{0}$ is the preindustrial non-marine base cation concentrations (assumed to be adequately represented by present day base cations, $B C$ ) and $A N C_{\text {lim }}$ is the critical acid-neutralizing capacity limit chosen to correspond to a threshold of protection for an ecosystem or individual species. Due to strong influence of organic acids, $A N C_{\text {lim }}$ of $75 \mu$ eq $\mathrm{L}^{-1}$ has been chosen for Alberta (WRS 2004), higher than elsewhere in Canada (40 $\mu \mathrm{eq}$ $\mathrm{L}^{-1}$; Henriksen et al. 2002). For further details on the SSWC see Henriksen \& Posch (2001).

\section{RESULTS AND DISCUSSION}

Lake water $\delta^{18} \mathrm{O}$ and $\delta^{2} \mathrm{H}$ compositions for the 20022008 study period plot along very similar local evaporation lines (LEL, Fig. 2) which suggests similar yearto-year heavy-isotope enrichment responses to open water evaporation (Gibson et al. 2008). The LEL is similar to that reported by Bennett et al. (2008) based on averages for 2002 to 2004 and similar to that found in other regional surveys (Gibson et al. 2005). Degree of offset from the meteoric water line for an individual lake is proportionate to the fraction of water loss by evaporation, and is therefore inversely proportional to the rate of flushing, which is enhanced both by precipi- 


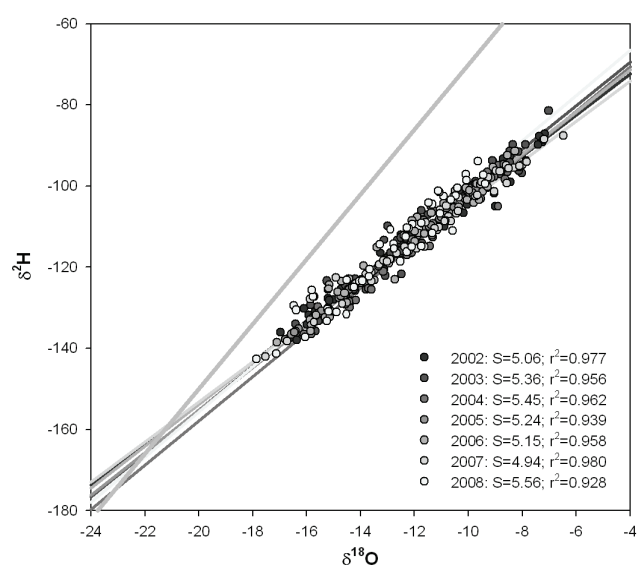

Fig. 2. $\delta^{2} \mathrm{H}-\delta^{18} \mathrm{O}$ plot of all the lakes surveyed during the study period. Units are in per mil. The grey line away from data points represents Global Meteoric Water Line (GMWL).
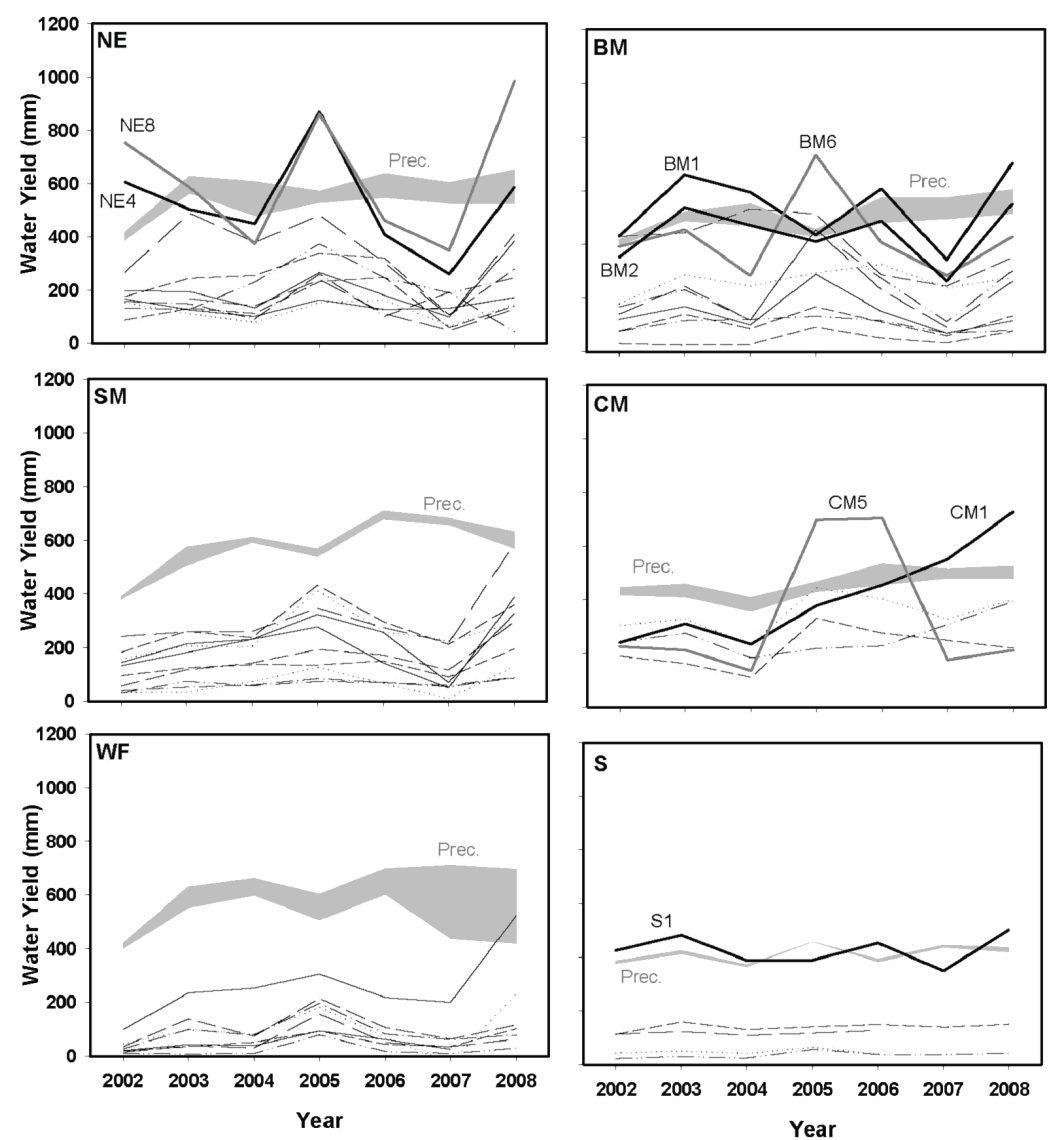

Fig. 3. Annual variation in water yield to the lakes in different regions. Gray shading represents the range in annual precipitation amounts in each region. The bold lines represent lakes (NE8, NE4, BM1, BM2, BM6, CM1, CM5, and S1) with anomalously high $W_{Y}$ (during some years $>100 \%$ of precipitation).

tation on the lake and $W_{Y}$ from the land surface (i.e., runoff).

The IMB derived estimates of $W_{Y}$ show considerable inter-annual variability over the 2002 to 2008 period both among lakes and between regions (Fig. 3). As expected, the estimated $W_{Y}$ from drainage basins to most lakes is less than $50 \%$ of the depth of precipitation. A few lakes are found to have anomalously high $W_{Y}$, and for some years appear to exceed $100 \%$ of precipitation (Fig. 3). It is evident that these lakes either have contributing watershed areas that are not accounted for in the GIS delineation, or alternatively may be fed by additional sources of water in addition to precipitationderived runoff. The source of this inflow could include regional groundwater discharge or possibly contributions from melting permafrost. Lakes with anomalously 
high water yield are in fact known to be situated in areas where the discontinuous permafrost is in a state of disequilibrium (Vitt et al. 2000). As such, degradation of permafrost may be a source of additional water in some catchments, although this remains to be verified.

The inter-annual variations in $W_{Y}$ have some common features across the region including peaks corresponding to 2003, 2005, and 2008 (Fig. 4a). The magnitude of these peaks differs between lakes and regions; however, they do correspond to hydrological years (September-August) with high amounts of total precipitation (Tab. 1). Despite the similarity in total precipitation for these years, the estimated $W_{Y}$ was higher for 2005, possibly reflecting the importance of antecedent moisture conditions, and factors such as the timing of the moisture availability.
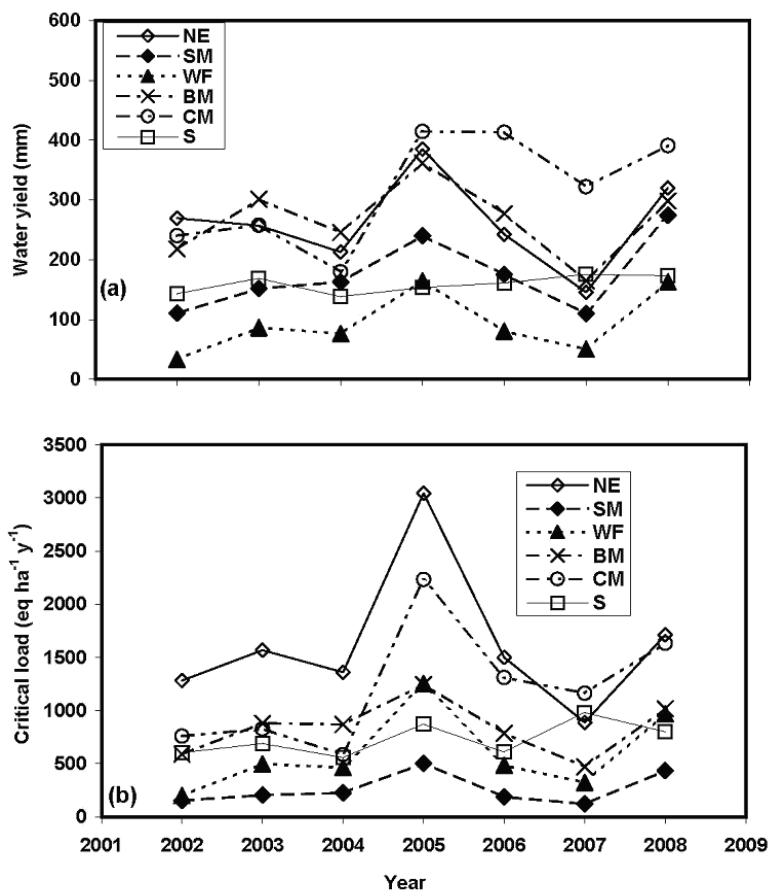

Fig. 4. Inter-annual variation in average (a) water yield and (b) critical load for lakes in each study region.

Based on the average $W_{Y}$, the study sub-regions appear to be divided into two categories: regions where average $W_{Y}$ during the study period was around or higher than $180 \mathrm{~mm} \mathrm{y}^{-1}$ (NE, CM, and BM, Fig. 4a) and the regions where average $W_{Y}$ was less than $180 \mathrm{~mm} \mathrm{y}^{-1}$ (SM, S, WF; Fig. 4a). Lakes in the regions with higher average $W_{Y}$ had relatively higher degree of inter-annual variation in $W_{Y}$ compared to the regions with lower average $W_{Y}$.

The critical loads calculated using the IMB also showed strong variations, inter-annually and between subregions (Fig. 4b, 5 \& 6). As would be expected given Eqn [1]. The calculated $C L_{A}$ values closely follow the interannual variability in $W_{Y}$ with the highest average critical loads occurring during 2005 for all regions (Fig. 4b \& 5). During the 2002-2008 period, the highest average critical load was observed for lakes in the NE region (1626.4 \pm $1551 \mathrm{eq} \mathrm{ha}^{-1} \mathrm{y}^{-1}$ ) and the lowest average critical load was found for lakes in the Stony Mountains (SM; $261.3 \pm 470.3$ eq $\left.\mathrm{ha}^{-1} \mathrm{y}^{-1}\right)$. The regions with the lower average $W_{Y}$ also had the lower critical loads.

Tab. 1. Average temperature and precipitation totals reported for the meteorological station at Fort McMurray. Averages (temperature) and totals (precipitation) were determined for the period of first arrival of snow (September) to the timing of the lake sampling (August the following year) to better represent the hydrological year represented by late summer lake sampling.

\begin{tabular}{ccc}
\hline & $\begin{array}{c}\text { Average temperature } \\
\text { (Sept.-Aug.) }\end{array}$ & $\begin{array}{c}\text { Total Precipitation } \\
\text { (Sept.-Aug.) }\end{array}$ \\
\hline $2001-2002$ & -0.97 & 377.2 \\
$2002-2003$ & -0.47 & 378.8 \\
$2003-2004$ & -0.26 & 304.7 \\
$2004-2005$ & 0.05 & 395.0 \\
$2005-2006$ & 2.85 & 320.0 \\
$2006-2007$ & -0.57 & 254.5 \\
$2007-2008$ & -0.91 & 345.5 \\
\hline
\end{tabular}

There is a positive relationship between the critical load and $W_{Y}$, with high $W_{Y}$ lakes generally having higher $C L_{A}$ values (Fig. 7a). Closer examination of data (Fig. 7a) suggests three different types of relationships between $C L_{A}$ and $W_{Y}$ in the lakes sampled in this survey. Lakes sampled from the Stony Mountains (SM) region plot along the low slope $C L_{A}-W_{Y}$ trajectory, with large ranges in $W_{Y}$ but a small range in $C L_{A}$. This suggests that increases in $W_{Y}$ at these lakes result in only limited increases in $C L_{A}$. Lakes in the Shield (S) region plot along the medium slope $C L_{A}-W_{Y}$ line, and have the least scatter $\left(r^{2}=0.94\right)$. These lakes seem to have a very predictable increase in $C L_{A}$ per increase in $W_{Y}$. Lakes located in the region West of Fort McMurray (WF) tended to plot along the high slope $C L_{A}-W_{Y}$ trajectory, having a very large range in $C L_{A}$ values, despite a limited range in $W_{Y}$ estimates. Lakes in the Northeast and Birch Mountains (NE and BM, respectively) display complex responses, plotting across all of the $C L_{A}-W_{Y}$ trajectories.

To some extent, these regional groups are also evident in the relationships between $C L_{A}$ and base cation concentrations (BC, Fig. 7b). Also, within a given region, lakes can have very different $\mathrm{BC}$ concentrations. The distinctive characterization of lakes from different regions with respect to their $\mathrm{BC}$ availability and $W_{Y}$ variability is also evident in the groupings in figure $7 \mathrm{c}$. The variations in $W_{Y}, C L_{A}$ and $\mathrm{BC}$ suggest that there are different degrees of sensitivity both in terms of hydrology and geochemistry for the region.

\subsection{Implications}

Efforts to improve $C L_{A}$ estimates have recently focussed on improving the quality of inputs to existing 

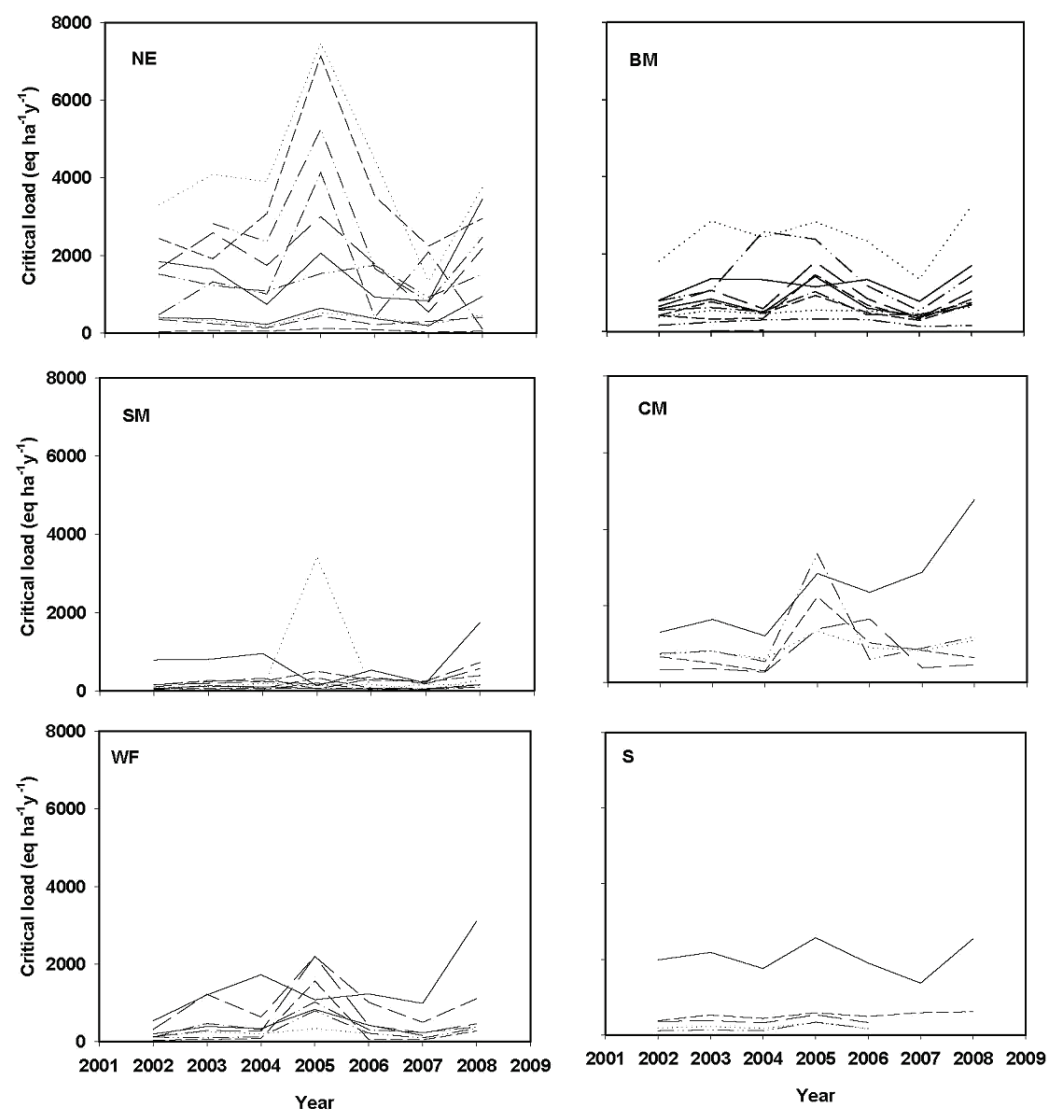

Fig. 5. Annual variation in critical load for the lakes in different regions.

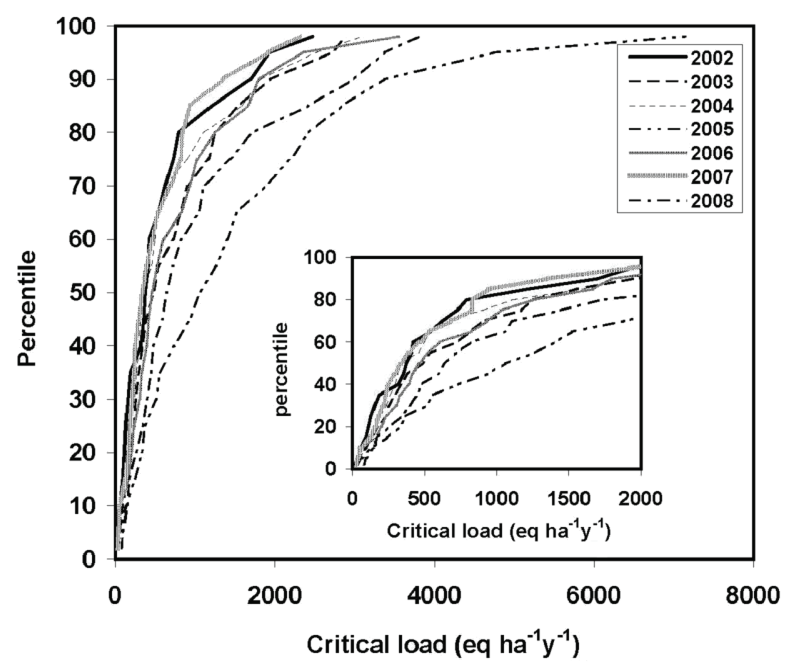

Fig. 6. Cumulative percentile distribution of critical loads for each year.

critical load models. As we have shown in this paper, and in previous assessments (Bennett et al. 2008; Gibson et al. 2010, this issue; Scott et al. 2010, this issue), uncertainty in critical loads can be reduced by using site-specific estimates of hydrology. The approach of applying long-term average grid-based runoff estimates in the SSWC models has been found to overestimate $C L_{A}$ for the majority of lake surveys examined in west- ern Canada (Gibson et al. 2010, this issue). The results from 2002-2008 sampling suggest that there is also considerable temporal variability in the $W_{Y}$ to lakes (Fig. $3 \& 4 a)$. Availability of extensive data, such as in the present study, on temporal variations in site-specific $W_{Y}$ is not common for critical loads estimation in Canada, so the knowledge of inter-annual or seasonal sensitivity of these estimates to hydrology is rather limited. Here 
we use the inter-annual variation to investigate the sensitivity of $C L_{A}$ estimates to hydrology, however, the temporal component is also of importance given the potential sensitivity of aquatic organisms to episodic or extreme events (White et al. 2000).

The results from this study show that inter-annual variability in hydrological regime of a lake can have direct consequence for the critical acid load estimate of that lake. In general, high $W_{Y}$ to the lakes leads to increase in the critical load values. In other words, hydrologic cycles of drought and flood can lead to acidification and de-acidification of lakes. The effect on regional critical load distributions is also apparent (Fig. 6). Despite being selected as representative of the most acid sensitive lakes in the region, these critical load estimates are evidently higher than other western Canadian provinces (3.6-15.3 eq ha ${ }^{-1} \mathrm{y}^{-1}$; Gibson et al. 2010, this issue), which is attributed mainly to buffering effects of carbonate rocks and carbonate-rich glacial till which mantles the region. Note that the selective approach used to define the lake network makes it problematic to compare statistically with other Western Canada lake surveys (Gibson et al. 2010, this issue). For example, calculation of the $5^{\text {th }}$ percentile value of the survey results is not done for this survey as it is only viewed as a useful guide for determining regional critical loads if the survey samples are truly representative of the entire regional lake population (Jeffries \& Ouimet 2005)

It has been argued that since critical loads are in most cases estimated from water chemistry on point-intime samples, they should be regarded as catchment and time-specific values (White et al. 2000). The interannual ranges in $C L_{A}$ values calculated on a year-byyear basis over the 7-year monitoring period provide an indication of the temporal sensitivity of critical load estimates to hydrology. Due to different catchment configurations in the 50 lakes, site-specific estimates of $W_{Y}$ also improve ability to capture spatial variability among the lakes. Incorporating uncertainty estimates around site-specific estimates of $W_{Y}$ to reflect expected ranges in inter-annual variations could be used to construct a more accurate perspective on spatial and temporal variability in acid sensitivity across the region. The sensitivity of $C L_{A}$ to changes in hydrology on the interannual scale also highlights the possibility of shifts in these relationships under changing environmental conditions, such as under climate or land use change (e.g., permafrost melt or wide-spread regional development).

The differential sensitivity observed in $C L_{A}-W_{Y}$ relationships (Fig. 7a), suggests that drainage characteristics can influence acid sensitivity. The geology and soil properties of each catchment plays a significant role in determining the critical load of lakes as the formation of base cations through mineral weathering is a major source of acid buffering solute to the lake. The correlation between the time-series of $C L_{A}$ and $W_{Y}$ and the positive relationship between $C L_{A}$ and $W_{Y}$ suggests that the transfer of soil generated alkalinity is relatively higher during high $W_{Y}$ year compared to low $W_{Y}$ year leading to relatively higher critical load.
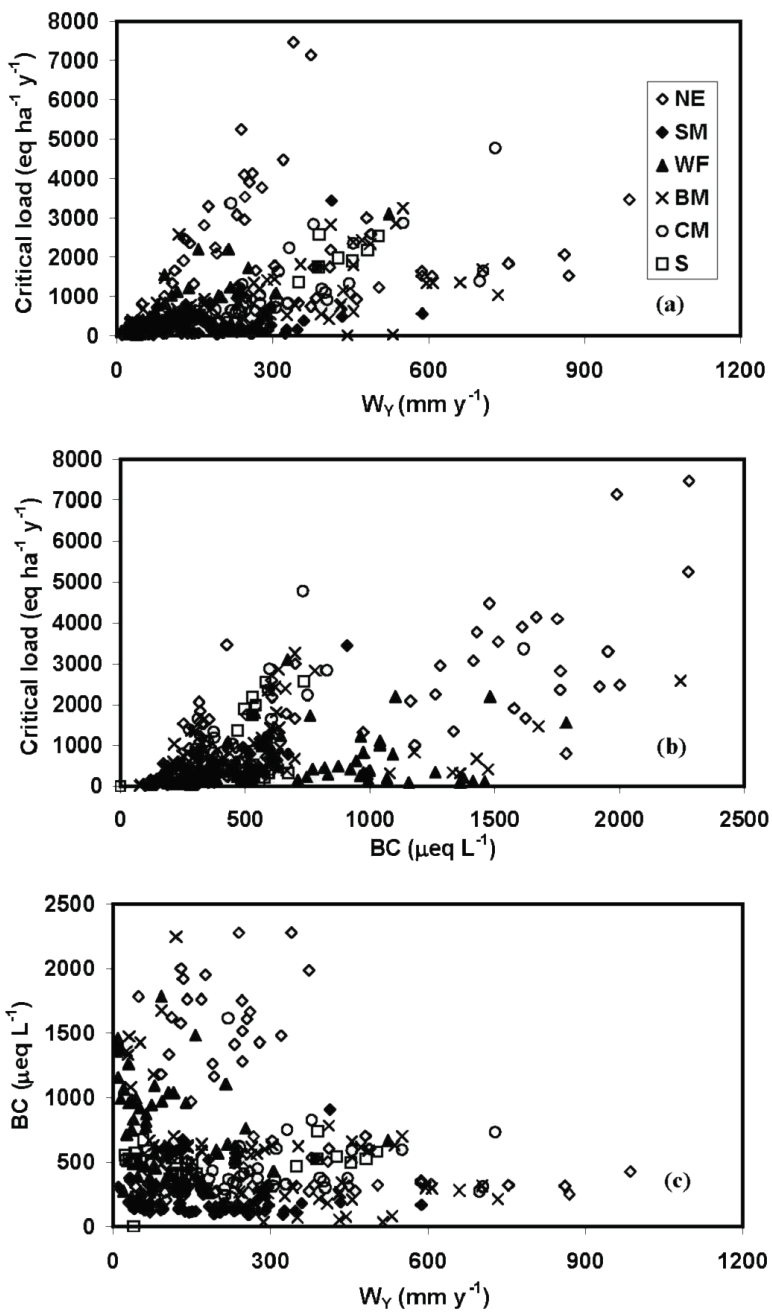

Fig. 7. Relationship between (a) critical load and water yield, (b) critical load and base cation concentration (BC) and (c) base cation concentration and water yield.

The SSWC model is the most commonly used approach in Canada for critical load estimation due to its simplicity compared to dynamic models. However, most lakes and soils are not in steady-state with their environment, particularly with changes in land use, deposition levels of pollutants, and potential change in climate (Lokke et al. 1996). Dynamic models have the benefit of being able to estimate the pattern, time-scales and magnitude of long-term change in surface water chemistry to changes in rates of acidic atmospheric deposition (Cosby et al. 2001). Since the SSWC does not take into consideration the time-dependence of processes relevant to acidification of surface water, it is unable to predict the gradual chemical response of a receptor to changing depositions (Forsius et al. 1998). 
The ability of dynamic models to predict time-scales for changes has resulted in growing interest in applying these types of models. If the dynamic models are to be used in future for predicting the acidification or recovery of Canadian freshwater resources, it is essential that we take steps which are vital for implementation of these models with lower uncertainty. Use of site specific hydrology monitored inter-annually may therefore offer a significant improvement for examining dynamic response of lakes to acidification.

The generation of $\mathrm{SO}_{\mathrm{x}}$ and $\mathrm{NO}_{\mathrm{x}}$ emissions related to the extraction and processing of bitumen in northeastern Alberta has made definition of critical loads in the Athabasca Oil Sands Region (AOSR) a priority. The results of this study and Gibson et al. (2010, this issue) highlight the sensitivity of $C L_{A}$ estimates to spatial and temporal variations in hydrology, that are particularly relevant in the AOSR. The region is characterized by high lake-to-lake variability in runoff, and includes innumerable small and large, ungauged lakes. Operationally, isotope mass balance provides a means for characterizing water yield for a large number of targeted systems based primarily on water sampling, and may be used to track longer-term changes related to climate and development-related effects. While the Boreal Plains region appears less sensitive to acid deposition than adjacent Shield regions, low runoff lakes still exist that are evidently highly sensitive to potential acid deposition. The overall observation that hydrologic change can drive acidification of lakes is of particular concern if we consider that drought due to development or decline in permafrost melt may be expected to occur in future in the AOSR.

\section{CONCLUSIONS}

The present study analyzes the sensitivity of critical acid load to inter-annual variation in hydrology. The study takes advantage of a monitoring network of 50 lakes in northeastern Alberta and provides an outlook on the inter-annual variations in hydrology and their impact on critical acid loads for the region. The site-specific water yield estimates obtained using isotope mass balance method was used for this purpose. In general, both water yields and critical acid loads were highly variable over the study period with distinct variations among lakes and different regions. The highest average critical load was observed for lakes in the northeastern part of Fort McMurray $\left(1626.4 \pm 1551 \mathrm{eq} \mathrm{ha}^{-1} \mathrm{y}^{-1}\right)$ and the lowest average critical load was found for lakes in the Stony Mountains (SM; $261.3 \pm 470.3 \mathrm{eq} \mathrm{ha}^{-1} \mathrm{y}^{-1}$ ). There was a positive relationship between the critical load and $W_{Y}$, with high $W_{Y}$ lakes generally having higher critical load values. Due to lack of reliable atmospheric deposition data for each region, exceedances could not be estimated during the present study. Ongoing efforts to improve monitoring of atmospheric deposition in the region by organizations such as the Wood Buffalo
Environmental Association are required to allow for a definitive assessment of critical load exceedance in the future.

\section{ACKNOWLEDGEMENTS}

This research was supported by the Cumulative Environmental Management Association and NSERC Discovery and CRD Grants to John Gibson.

\section{REFERENCES}

Beamish, R.J. \& H.H. Harvey. 1972. Acidification of the LaCloche Mountain lakes, Ontario, and resulting fish mortalities. J. Fish. Res. Board Can., 29: 1131-1143.

Bennett, K.E., J.J. Gibson \& P.M. McEachern. 2008. Water yield estimates for critical loadings assessment: comparisons of gauging methods versus and isotopic approach. Can. J. Fish. Aquat. Sci., 65: 83-99.

Bowen, G.J. \& B. Wilkinson. 2002. Spatial distribution of $\delta^{18} \mathrm{O}$ in meteoric precipitation. Geology, 30: 315-318.

Coplen, T.B. 1996. New guidelines for reporting stable hydrogen, carbon, and oxygen isotope-ratio data. Geochim. Cosmochim. Acta, 60: 3359-3360.

Cosby, B.J., R.C. Ferrier, A. Jenkins \& R.F. Wright. 2001. Modelling the effects of acid deposition: refinements, adjustments and inclusion of nitrogen dynamics in the MAGIC model. Hydrol. Earth Sys. Sci., 5: 499-517.

Craig, H. 1961. Isotopic variations in meteoric waters. Science, 133: 1702-1703.

Devito, K., I. Creed, T. Gan, C. Mendoza, R. Petrone, U. Silins \& B. Smerdon. 2005. A framework for broad-scale classification of hydrologic response units on the Boreal Plain: is topography the last thing to consider? - Invited Review. Hydrol. Process., 19: 1705-1714.

Dillon, P.J., D.S. Jeffries, W. Snyder, R. Reid, N.D. Yan, D. Evans, J. Moss \& W.A. Scheider. 1978. Acid precipitation in south-central Ontario: recent observations. J. Fish. Res. Board Can., 35: 809-815.

Forsius, M., M. Alveteg, A. Jenkins, M. Johansson, S. Kleemola, A. Lukewille, M. Posch, H. Sverdrup \& C. Walse. 1998. MAGIC, SAFE, and SMART model applications at integrated monitoring sites: Effects of emission reduction scenarios. Water Air Soil Pollut., 105: 21-30.

Gibson, J.J., E.E. Prepas \& P. McEachern. 2002. Quantitative comparison of lake throughflow, residency, and catchment runoff using stable isotopes: modelling and results from a regional survey of Boreal lakes. J. Hydrol., 262: 128-144.

Gibson, J.J., S.J. Birks \& T.W.D. Edwards. 2008. Global prediction of $\delta_{\mathrm{A}}$ and $\delta^{2} \mathrm{H}-\delta^{18} \mathrm{O}$ evaporation slopes for lakes and soil water accounting for seasonality. Global Biogeochem. Cycles, DOI: 10.1029/2007GB002997.

Gibson, J.J., S.J. Birks, D.S. Jeffries, S. Kumar, K. Scott, J. Aherne \& D.P. Shaw. 2010. Site-specific estimates of water yield applied in regional acid sensitivity surveys across western Canada. J. Limnol., 69(Suppl. 1): 67-76. DOI: 10.3274/JL10-69-S1-08.

Gibson, J.J., T.W.D. Edwards, S.J. Birks, N.A. St. Amour, W. Buhay, P. McEachern, B.B. Wolfe \& D.L. Peters. 2005. Progress in isotope tracer hydrology in Canada. Hydrol. Process., 19: 303-327.

Henriksen, A., L. Lien \& T. Traaen. 1988. Lake acidification in Norway - Present and predicted chemical status. Ambio, 17: 259-266.

Henriksen, A. \& M. Posch. 2001. Steady-state models for calculating critical loads of acidity for surface waters. Water Air Soil Pollut. Focus, 1: 375-398. 
Henriksen, A., P.J. Dillon \& J. Aherne. 2002. Critical loads of acidity for surface waters in south-central Ontario, Canada: regional application of the Steady-State Water Chemistry (SSWC) model. Can. J. Fish. Aquat. Sci., 59: 1287-1295.

Henriksen, A., J. Kamari, M. Posch \& A. Wilander. 1992. Critical loads of acidity: Nordic surface waters. Ambio, 21: 356-363.

Heywood, E., J. Hall \& B. Reynolds. 2006. A review of uncertainties in the inputs to critical loads of acidity and nutrient nitrogen for woodland habitats. Environ. Sci. Pol., 9: 78-88.

Jeffries, D.S. \& R. Ouimet (Eds). 2005. Chapter 8: Critical Loads - Are they being exceeded? In: 2004 Canadian acid deposition science assessment. Environment Canada, Ottawa, Ontario: 341-368. (see http: //www.mscsmc.ec.gc.ca/saib/acid/assessment2004/pg41_e.html\#1).

Løkke, H., J. Bak, U. Falkengren-Grerup, R.D. Finlay, H. Ilvesniemi, P.H. Nygaard \& M. Starr. 1996. Critical loads of acidic deposition for forest soils: Is the current approach adequate? Ambio, 25: 510-516.

Mesinger, F., G. DiMego, E. Kalnay, K. Mitchell, P.C. Shafran, W. Ebisuzaki, D. Jovic, J. Woollen, E. Rogers, E.H. Berbery, M.B. Ek, Y. Fan, R. Grumbine, W. Higgins, H. Li, Y. Lin, G. Manikin, D. Parrish \& W. Shi. 2006. North American regional reanalysis: A long-term, consistent, high-resolution climate dataset for the North American domain, as a major improvement upon the earlier global reanalysis datasets in both resolution and accuracy. Bull. Amer. Meteorol. Soc., 87: 343-360.

Nilsson, J. \& P. Grennfelt (Eds). 1988. Critical loads for sulphur and nitrogen. Miljørapport 1988:15, NORD 1998:097, Nordic Council of Ministers, Copenhagen, Denmark: 418 pp.
Scott, K., B. Wissel, J.J. Gibson \& S.J. Birks. 2010. Chemical characteristics and acid sensitivity of boreal headwater lakes in northwestern Saskatchewan. J. Limnol., 69(Suppl. 1): 33-44. DOI: 10.3274/JL10-69-S1-05.

Schmidt, A., J.J. Gibson, I.R. Santos, M. Schubert \& K. Tattrie. (2010). The contribution of groundwater discharge to the overall water budget of Boreal lakes in Alberta estimated from a radon mass balance. Hydrol. Earth Sys. Sci.: (in press).

Sivapalan, M. 2003. Prediction in ungauged basins: a grand challenge for theoretical hydrology-invited commentary. Hydrol. Process., 17: 3163-3170.

Skeffington, R.A., P.G. Whitehead, E. Heywood, J.R. Hall, R.A. Wadsworth \& B. Reynolds. 2007. Estimating uncertainty in terrestrial critical loads and their exceedances at four sites in the UK. Sci. Tot. Environ., 382: 199-213.

Vitt, D.H., L.A. Halsey \& S.C. Zoltai. 2000. The changing landscape of Canada's western boreal forest: the current dynamics of permafrost. Can. J. For. Res., 30: 283-287.

Watt, W.D., D. Scott \& S. Ray. 1979. Acidification and other chemical changes in Halifax County lakes after 21 years. Limnol. Oceanogr., 24: 1154-1161.

White, C.C., R. Smart \& M.S. Cresser. 2000. Spatial and temporal variations in critical loads for rivers in N.E. Scotland: A validation of approaches. Water Res., 34: 19121918.

Whitfield, C.J., J. Aherne, J.J. Gibson, T.A. Seabert \& S.A. Watmough. (2010). The controls on boreal peatland surface water chemistry in northern Alberta, Canada. Hydrol. Process.: (in press).

WRS (Western Resource Solutions). 2004. Calculation of critical loads of acidity to lakes in the Athabasca Oil Sands Region. Report to the NOx-SOx committee, Western Resource Solutions, Calgary, Alberta: 60 pp. (plus 9 Appendices). 